The authors reported no conflicts of interest.

The Journal policy requires editors and reviewers to disclose conflicts of interest and to decline handling or reviewing manuscripts for which they may have a conflict of interest. The editors and reviewers of this article have no conflicts of interest.

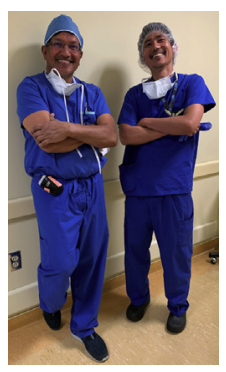

\section{THE IMPORTANCE OF} LEFT VENTRICULAR SIZE

\section{To the Editor:}

We read with great interest the article by Omer and colleagues ${ }^{1}$ about the relationship among decreased left ventricular ejection fraction (LVEF), failure to rescue, and late survival in patients who underwent isolated coronary artery bypass grafting (CABG). Data from the Veterans Affairs Surgical Quality Improvement Program included more than 60,000 patients with follow-up. LVEF was categorized as $35 \%$ or greater, $25 \%$ to $34 \%$, or less than $25 \%$. Postoperative complications were also categorized as no, 1 , or 2 or more complications. They found that decreased LVEF was associated with a higher incidence of complications and multiple complications relative to patients with LVEF greater than $35 \%$. Survival of patients who had complications was lower than of those without complications irrespective of LVEF. An association between decreased LVEF and 90-day and 180-day mortality was noted. Additionally, there were clear decrements in overall survival as LVEF decreased.

Omer and colleagues ${ }^{1}$ analyzed perioperative outcomes and late survival stratified by LVEF category. Historically, decreased LVEF has been associated with poor perioperative and long-term outcomes. ${ }^{2-4}$ However, most previous studies, including this present report, failed to apply left ventricle (LV) size as a variable to analyze perioperative outcomes in high-risk patients who underwent isolated CABG.

We have recently published our own institutional outcomes in patients with poor LVEF undergoing both

\footnotetext{
The Editor welcomes submissions for possible publication in the Letters to the Editor section that consist of commentary on an article published in the Journal or other relevant issues. Authors should: • Include no more than 500 words of text, three authors, and five references. • Type with double-spacing. • See http://jtcs.ctsnetjournals.org/ misc/ifora.shtml for detailed submission instructions. • Submit the letter electronically via jtcvs.editorialmanager.com. Letters commenting on an article published in the JTCVS will be considered if they are received within 6 weeks of the time the article was published. Authors of the article being commented on will be given an opportunity of offer a timely response ( 2 weeks) to the letter. Authors of letters will be notified that the letter has been received. Unpublished letters cannot be returned.
}

isolated CABG and valvular surgery. ${ }^{5}$ We conducted a study comparing postoperative outcomes after cardiac surgery among patients with preserved LVEF $(>60 \%)$, patients with LVEF less than $20 \%$ and LV size less than $5.4 \mathrm{~cm}$, and patients with LVEF less than $20 \%$ and LV size greater than $5.5 \mathrm{~cm}$ using propensity matched analysis. We also stratified surgical outcomes by type of procedure (isolated CABG, isolated valve, or valve and CABG). Our study revealed that there was no statistically significant difference in terms of mortality, major morbidity, and prolonged hospital stay between patients with LVEF less than $20 \%$ and LV size less than $5.4 \mathrm{~cm}$ and those with preserved LVEF who underwent isolated CABG. In contrast, the combination of poor LV function and a dilated LV led to significantly worse outcomes in patients undergoing isolated CABG.

We suggest that the present study by Omer and colleagues ${ }^{1}$ would have been strengthened by the inclusion of LV size as a predictor variable. Although we demonstrated that early survival was influenced by LV size, the authors may show that the ability to rescue these patients from complications may be limited and that the longterm effect of perioperative complications might be greater in patients with LV dysfunction and an enlarged LV.

\section{Naoto Fukunaga, $M D$ \\ Vivek Rao, MD, PhD \\ Division of Cardiovascular Surgery \\ Peter Munk Cardiac Centre \\ Toronto General Hospital, \\ University of Toronto, University Health Network \\ Ontario, Canada}

\section{References}

1. Omer S, Adeseye A, Jimenez E, Cornwell LD, Massarweh NN. Low left ventricular ejection fraction, complication rescue, and long-term survival after coronary artery bypass grafting. J Thorac Cardiovasc Surg. 2021;163: 111-9.

2. Christakis GT, Weisel RD, Fremes SE, Ivanov J, David TE, Goldman BS, et al Coronary artery bypass grafting in patients with poor ventricular function. Cardiovascular Surgeons of the University of Toronto. J Thorac Cardiovasc Surg. 1992; 103:1083-91.

3. Appoo J, Norris C, Merali S, Graham MM, Koshal A, Knudtson ML, et al. Longterm outcome of isolated coronary artery bypass surgery in patients with severe left ventricular dysfunction. Circulation. 2004;110(Suppl II):II13-7.

4. Ahmed WA, Tuly PJ, Baker RA, Knight JL. Survival after isolated coronary artery bypass grafting in patients with severe left ventricular dysfunction. Ann Thorac Surg. 2009;87:1106-12.

5. Fukunaga N, Pinto Ribeiro RV, Lafreniere-Roula M, Manlhiot C, Badiwala MV, Rao V. Left ventricular size and outcomes in patients with left ventricular ejection fraction < 20. Ann Thorac Surg. February 16, 2020 [Epub ahead of print].

https://doi.org/10.1016/j.jtcvs.2020.06.126 